\title{
Robust Controller for Kaplan Hydroturbine Governor System Based on Fast Terminal Sliding Mode Control (FTSMC)
}

\author{
Samba Aimé Hervé ,Yeremou Tamtsia Aurelien, Nneme Nneme Leandre and Korassaï
}

\begin{abstract}
In this paper a fast terminal sliding mode control (FTSMC) is used for speed control of Kaplan hydroturbine governing system in the presence of load torque disturbance . The stability of the proposed controller is proved with the lyapunov function method.The results indicate that the proposed terminal sliding mode controllers not only have a faster response and allows to carry out high performances as well in precision as in finite time of convergence. Moreover, the comparisons of the dynamic performances between the proposed fast terminal sliding mode controllers (FTSMC) and non-singular fast terminal sliding mode controllers (NSTSMC), are discussed at the end of this paper, where the effectiveness and robustness superiority of the fast terminal sliding mode controller proposed also is been verified.
\end{abstract}

Index Terms-Finite Time Convergence, Hydroturbine Governing System, Terminal Sliding Mode Control.

\section{INTRODUCTION}

Recently, a new control design methods based on sliding mode controller (SMC) has been developed in [1,2,4-6,913,15]. Known by its robustness and its simplicity of implementation, the sliding mode control was largely used to control a broad class of nonlinear systems[4,8-12]. However, this type of control does not make it possible to maintain good performances of continuation in the presence of external disturbances. The disadvantage lies in the use of the function signs in the control law to ensure the passage of the phase of approach that of the sliding. This gives place to the phenomenon of chattering which consists of variations abrupt and fast of the control signal, which can excite the high frequencies of the process and damage it. To cure these problems, several approaches were presented in the literature [4-6,14,15]. With an aim of accelerating convergence, several authors made recourse to convergence in finite time by developing the terminal sliding mode control (TSMC). Indeed, this approach makes it possible to carry out high performances as well in precision as in finished time of convergence. In this work, we

DOI: http://dx.doi.org/10.24018/ejers.2020.5.8.2024

Published on August 31, 2020

Samba Aimé Hervé is with the National Advanced School of Engineering, University of Douala, Douala,Cameroon(e-mail:aimehervesamba@yahoo.fr).

Yeremou Tamtsia Aurelien is with the National Advanced School of Engineering, University of Douala, Douala, Cameroon (email:ayeremou@yahoo.fr).

Nneme Nneme Leandre ,Advanced Teacher, is with the Training College for Technical Education, University of Douala, Douala, Cameroon (emai:leandren@gmail.com).

Korassaï is with the Faculty of Science, University of Ngaoundere, Ngaoundere, Cameroon (e-mail:korassaipaul@gmail.com). propose an innovative controller based on fast terminal sliding mode control (FTSMC), is been adopted for controlling the speed of Kaplan hydro turbine governing system with ,who are considered by his robustness with respect to the errors of modeling and the external disturbances like its convergence in time finished thanks to its nonlinear sliding surface This innovative controller has been proved to track error accurately through Lyapunov stability analysis. System responses and controller efforts have been evaluated.

The results indicate that the TSMC controller perform in terms of the regulation quality and tracking errors in all simulation cases. Moreover, comparing to NSTSMC, the proposed FTSMC controller also show tremendous advantages in terms of reducing the convergence time of tracking errors in simulation cases. Accordingly, the main contributions of this paper can be summarized as follows:

1) A mathematical model of Kaplan hydro turbine governing system model (case of Edea-Cameroon hydroelectric power station) represented by nonlinear differential equations obtained from the known parameters of hydropower station and model will be used in the process of identification is proposed in this study.

2) The terminal sliding mode control schemes are first introduced into the governor design of Kaplan hydro turbine system to offer faster response speed and better regulation accuracy.

3) The finite-time convergence and stability analysis for Kaplan hydro turbine governing system model with designed fast terminal sliding mode controller is been verified by finite-time theory and Lyapunov stability theory.

The rest of this paper is organized as follows. In Section II, the dynamic model of model of Kaplan hydro turbine governing system is described. The methods of two main proposed controllers are introduced in Section III, in which a NTSMC and FTSMC are applied to the Kaplan hydroturbine governor system in presence of external disturbances. Simulation results are illustrated in section IV .Finally section V concludes this paper.

\section{HYDRO TURBINE GOVERNING SYSTEM DESCRIPTION AND MODELLING}

For the realization of our project, we have used the model of the Kaplan hydro turbine governing system of the EdeaCameroon hydroelectric power station. The process is consists 
of four parts including the hydro turbine model, generator model ,hydraulic servo system model and power system model.

\section{A. Hydro turbine Model}

The turbine of the power station is a Kaplan hydro turbine, thus modelling associated with this type of turbine is based on a non-linear model. The dynamic characteristics of the hydro turbine could be expressed as $[2,17,18]$ :

$$
\begin{aligned}
\frac{d q}{d t} & =-\frac{2}{\tau_{w} G_{0}} q+\frac{2 K_{t}}{\tau_{w} G_{0}} g \\
\frac{d g}{d t} & =\quad-\tau_{a} g+K_{a} u \\
P_{m} & =\quad 3 q-2 K_{t} g,
\end{aligned}
$$

Where $q, g, P_{m}, K_{t}, \tau_{a}, K_{a}$ and $u$ represent the water flow in the turbine, winnowing, the mechanical power, turbine gain,water starting time , the constant time of the servo-motor, gain Comparison results of real power output at the generator terminals

\section{B. Servo-valve-Servo-motor unit Model}

The model of the servo valve is given by [1]: With the parameters of the hydropower station, we obtain:

$$
G_{s}(s)=\frac{94.34}{1+3.043 s+0.03043 s^{2}},
$$

\section{Power system model}

More details about power system modelling can be seen in $[2,19,20]$. The dynamic of the electrical generator is represented by differential equation, describing the dynamics of the exciting winding:

$$
\dot{E}_{q}=\frac{1}{T_{d}}\left[E_{f d}(t)-E_{q}(t)-I_{d}(t)\left(x_{d}-x_{d}^{\prime}\right)\right]
$$

Where $E_{q}$ is the transient voltage in quadratic of the synchronous generator ; $T_{d}$ is the damping torque coefficient ; $E_{f d}$ is the field voltage of the synchronous generator; $I_{d}$ is the direct component of the current of the stator; $x_{d}$ is the total $\mathrm{d}$-axis synchronous reactance of the synchronous machine and $x_{d}^{\prime}$ is the transient reactance of the synchronous generator. The mechanical dynamics of the machine is described in terms of rotor speed of the generator $\Delta \omega$ compared to nominal speed $\omega_{0}$ and of the angle of the rotor angle of the synchronous generator. The mechanical equation of the motion is as follows:

$$
\begin{gathered}
\frac{d}{d t} \delta(t)=\omega_{0} \Delta \omega(t) \\
\Delta \dot{\omega}(t)=-\frac{D}{2 J} \Delta \omega(t)+\frac{1}{2 J}\left(P_{m}(t)-P_{e}(t)\right)
\end{gathered}
$$

where $\delta$ is the power angle of the generator, $P_{m}$ is the mechanical input power and $P_{e}$ is the electrical power. TableI present the parameters of the power system.

With an aim of establishing the algebraic equations of the system, one defines the following reactances :

$$
x_{d s}=x_{d}+x_{s},
$$

TABLE I

PARAMETERS OF THE POWER SYSTEM

\begin{tabular}{llll} 
Parameters & Description & Value & Unit \\
\hline$J$ & Inertia constant & 5200000 & $\mathrm{Kg} \cdot \mathrm{m}^{2}$ \\
$P_{m}$ & Mechanical power & 19 & $\mathrm{MW}$ \\
$\mathrm{D}$ & $\begin{array}{l}\text { Mechanical damping } \\
\text { torque coefficient }\end{array}$ & 1.4202 & $\mathrm{p} . \mathrm{u}$ \\
& & \\
\hline
\end{tabular}

$$
\begin{aligned}
& x_{d s}^{\prime}=x_{d}^{\prime}+x_{s}, \\
& x_{q s}=x_{q}+x_{s}, \\
& x_{s}=x_{T}+x_{L},
\end{aligned}
$$

Table-II present the reactances of the power system.

TABLE II

REAC- TANCES OF THE POWER SYSTEM

\begin{tabular}{llll} 
Reactance & Description & Value & Unit \\
\hline$x_{d}$ & $\begin{array}{l}\text { Total d-axis synchronous re- } \\
\text { actance }\end{array}$ & 1.19 & p.u \\
$x_{q}$ & $\begin{array}{l}\text { Total q-axis synchronous re- } \\
\text { actance }\end{array}$ & 2.01 & p.u \\
$x_{d}^{\prime}$ & $\begin{array}{l}\text { Total d-axis transient reac- } \\
\text { tance }\end{array}$ & 0.28 & p.u \\
$x_{T}$ & $\begin{array}{l}\text { Reactance of the trans- } \\
\text { former } \\
\text { Reactance of the transmis- } \\
\text { sion line }\end{array}$ & 0.12 & p.u \\
$x_{L}$ & 0.11 & p.u \\
\hline
\end{tabular}

If resistances of the stator windings and that of the line are neglected, the components of the stator current are written as follows:

$$
\begin{gathered}
I_{d}(t)=\frac{E_{q}(t)-V_{s} \cos (\delta(t))}{x_{d s}^{\prime}}, \\
I_{q}(t)=\frac{V_{s} \sin (\delta(t))}{x_{q s}},
\end{gathered}
$$

Where $V_{d}, V_{q}$ are the stator voltage in d-axis and q-axis circuit ; $V_{s}$ the terminal voltage. The real power output at the generator terminals is given by:

$$
\begin{aligned}
P_{e}(t)= & V_{s} \sin (\delta(t)) \cdot I_{d}(t) \\
& +V_{s} \cos (\delta(t)) \cdot I_{q}(t)
\end{aligned}
$$

According to equations Eq. (10), Eq. (11) and Eq. (12), one obtains:

$$
\begin{aligned}
P_{e}(t)= & \frac{V_{s} E_{q}(t)}{x_{d s}^{\prime}} \sin (\delta(t)) \\
& -\frac{x_{q}-x_{d}^{\prime}}{x_{q s}^{\prime} x_{d s}^{\prime}} V_{s}^{2} \sin (\delta(t)) \cos (\delta(t))
\end{aligned}
$$

We can also write the equation of the terminal voltage in the form:

$$
V_{t}^{2}=V_{d}^{2}+V_{q}^{2},
$$




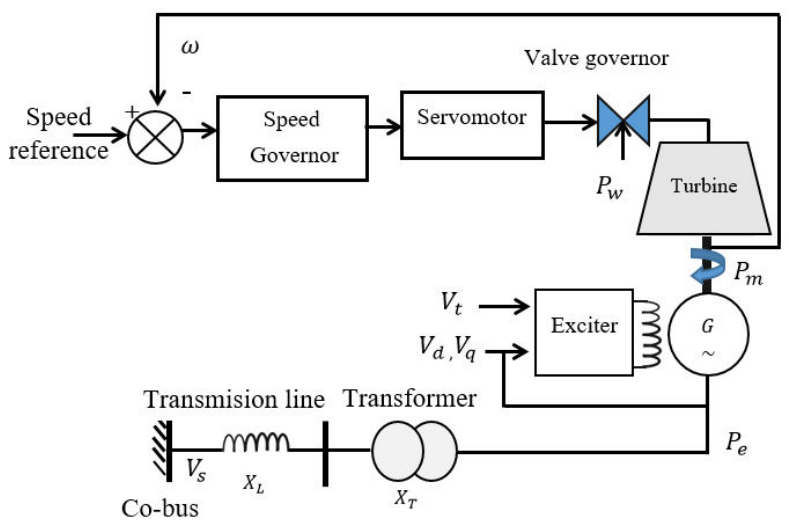

Fig. 1. Closed loop block diagram of hydroturbine governor system and power system.

Where

$$
\begin{gathered}
V_{d}=x_{q}^{\prime} I_{q}, \\
V_{q}=E_{q}-x_{q}^{\prime} I_{d},
\end{gathered}
$$

The closed loop block diagram of hydroturbine governor system and power system are illustrated in Fig.1

\section{Model identification of the hydro turbine governor system}

The open loop response of the nominal regime of the model of Kaplan hydroturbine governor system is approximately a second order system, we thus choose a model of the second order of the form:

$$
T(s)=\frac{Y(s)}{R(s)}=\frac{K}{1+2 \frac{\xi}{\omega_{n}} s+\left(\frac{s}{\omega_{n}}\right)^{2}},
$$

Where $K$ is the static profit of the system, $\omega_{n}$ the natural pulsation of the system, $\xi$ the damping ratio, $\mathrm{Y}(\mathrm{s})$ the output signal and $\mathrm{R}(\mathrm{s})$ the input signal. We carry out the identification of the diagram block. The following values are obtained: $K=$ $0.8780 ; \xi=1.4202 ; \omega_{n}=0.6397$. The transfer function of the model obtained is:

$$
T(s)=\frac{4.672}{s^{2}+2.951 s+5.321},
$$

Fig.2 shows the index responses of the systems and the Model

According to Fig.2, It appears that the response of the model tends gradually to that of the system. The state space describing the model of the system is given as follows

$$
\begin{array}{rlll}
\dot{x}_{1} & = & -2.951 x_{1} & -2.6605 x_{2}+2 u \\
\dot{x}_{2} & = & 2 x_{1} & \\
\omega & = & 1.168 x_{2}
\end{array}
$$

\section{SYNTHESIS OF NON-SINGULAR TERMINAL SLIDING} MODE CONTROL (NTSMC) AND FAST TERMINAL SLIDING

MODE CONTROL (FTSMC) FOR THE HYDRO TURBINE

\section{GOVERNOR SYSTEM}

\section{A. Traditional terminal sliding mode controller}

Consider the dynamical second-order system of the following form:

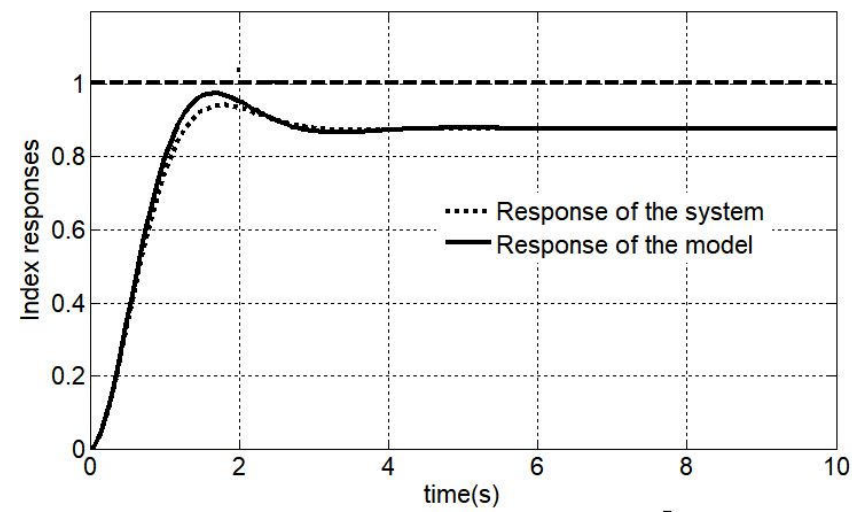

Fig. 2. Index responses of the systems and the model.

$$
\begin{aligned}
& \dot{x}_{1}=x_{2} \\
& \dot{x}_{2}=f(x)+g(x)+b(x) \cdot u
\end{aligned}
$$

Where $x=\left[\begin{array}{ll}x_{1} & x_{2}\end{array}\right]^{T}$ is the state vector of the system , $f(x)$ and $b(x)$ are continuous functions representing system dynamics, $g(x)$ represent uncertainties and the disturbances such as $\|g(x)\| \leq \kappa ; \kappa>0$ and $u$ is the scalar control input of the system. The conventional TSMC is described by the first order sliding variable given by[5]:

$$
s=x_{2}+\beta x_{1}^{q_{1} / p_{1}}
$$

Where $\beta>0$ is a parameter of constant, $p$ and $q$ is positive odd integers satisfying $p_{1}>q_{1}$. The sufficient condition of existence of the TSMC is:

$$
s \dot{s}<-\eta|s| ; \eta>0
$$

For the system Eq. (20), the order is calculated by satisfying the attegnability condition:

$$
\dot{s}=-(\kappa+\eta) \operatorname{sgn}(s)
$$

with $\eta>0$.

$$
\begin{aligned}
u= & -b^{-1}(x)\left(f(x)+\beta \frac{q_{1}}{p_{1}} x_{1}^{q_{1} / p_{1}-1} x_{2}\right. \\
& +(\kappa+\eta) \operatorname{sgn}(s)
\end{aligned}
$$

If $s(0) \neq 0$,the system reaches the sliding surface $s=0$ in finished time $t_{r}$ which satisfies:

$$
t_{r} \leq \frac{|s(0)|}{\eta}
$$

On this surface, the dynamics of the system is defined by the nonlinear equation:

$$
x_{2}+\beta x_{1}^{q_{1} / p_{1}}=\dot{x}_{1}+\beta x_{1}^{q_{1} / p_{1}}=0
$$

In the law of order Eq. (24), the term containing $x_{1}^{q_{1} / p_{1}-1} x_{2}$ can cause a singularity if $x_{2} \neq 0$ when $x_{1}=0$.This situation does not occur in the ideal mode sliding $s=0$ owing to the fact that $x_{2}=-\beta x_{1}^{q_{1} / p_{1}}$ as long as $q_{1}<p_{1}<2 q_{1}$ what returns term $x_{1}^{q_{1} / p_{1}-1} x_{2}$ equivalent with $x_{1}^{\left(2 q_{1}-p_{1}\right) / p_{1}-1}$ which is not singular. The difficulty of singularity can arise in 
the phase of convergence if $x_{2} \neq 0$ when $x_{1}=0$. the next algorithm will be based on non-singular terminal sliding mode control (NTSMC)

\section{B. Design of NTSMC for Kaplan hydroturbine governor sys- tem}

Let us suppose that speed desired is $\omega_{r}$, the tracking error is defined as follows:

$$
e=\omega-\omega_{r}
$$

Let us define the error dynamics as:

$$
\dot{e}=2.336 x_{1}-\dot{\omega}_{r}
$$

and

$$
\ddot{e}=-6.8935 x_{1}-6.2149 x_{2}+4.6720 u-\ddot{\omega}_{r}
$$

This controller is regarded as an approach suggested to cure the problem of singularity [11], his principle consists in proposing a sliding mode surface of the form:

$$
s=e+\frac{1}{\alpha} \dot{e}^{\frac{p_{2}}{q_{2}}}
$$

where $\alpha>0, p_{2}$ and $q_{2}$ are two positive odd integers, and $1<\frac{p_{2}}{q_{2}}<2$. The NSTSMC for the model of the hydro turbine governor system can be designed as :

$$
\begin{aligned}
u= & -4.66\left(-6.2138 x_{2}+\alpha \frac{q_{2}}{p_{2}} e^{2-q_{2} / p_{2}} \dot{e}\right. \\
& +(\kappa+\eta) \operatorname{sgn}(s)
\end{aligned}
$$

Taking $f(x)=-6.2138 x_{2}$ and $b^{-1}(x)=4.66$. The control law is presented as follow:

$$
\begin{aligned}
u= & -b^{-1}\left(f(x)+\alpha \frac{q_{2}}{p_{2}} e^{2-q_{2} / p_{2}} \dot{e}\right. \\
& +(\kappa+\eta) \operatorname{sgn}(s)
\end{aligned}
$$

Where $p=5, q=3, \eta=12$ and $\kappa=50$.

Theorem 1: The sliding mode surface Eq. (33) can ensure a finite time convergence to the equilibrium point of the hydro turbine governor system model.

One considers the Lyapunov function $V=\frac{1}{2} s^{2}$, its time derivative is:

$$
V=s \dot{s}=s\left(\dot{e}+\frac{1}{\alpha} \frac{p_{2}}{q_{2}} \dot{e}^{\frac{p_{2}}{q_{2}}-1} \ddot{e}\right)
$$

While replacing Eq. (20) in Eq. (33) it results from it: If we posed $\rho(e)=-\frac{1}{\alpha} \frac{p_{2}}{q_{2}} \eta e^{\left(p_{2} / q_{2}\right)-1}$ we will have:

$$
s \dot{s} \leq \rho(e)|s|
$$

with $\rho>0$ for $e \neq 0$. Consequently, if $e \neq 0$ the condition which ensures the Lyapunov stability is satisfied for $\rho>0$. The states of the system can reach the sliding mode $s=0$ in a finished time. This can be proven by replacing the form of the controller Eq. (32) in the system Eq. (20), from where we obtain:

$$
\begin{aligned}
\dot{e}= & -\frac{1}{\alpha}\left(\frac{p_{2}}{q_{2}} e^{2-\left(p_{2} / q_{2}\right)-1}\right) \dot{e} g(x) \\
& -(\kappa+\eta) \operatorname{sgn}(s)
\end{aligned}
$$

Thus, for $e=0$ we have:

$$
\dot{e}=g(x)-(\kappa+\eta) \operatorname{sgn}(s)
$$

For $s>0$ we have $\dot{e} \leq-\eta$ and $s<0, \dot{e} \geq \eta$ which shows that $e=0$ is not gravitational. That also means that there is a vicinity of $e=0$ such as for small $\delta>0$ which satisfies $|e|<\delta$ there exists $\dot{e} \leq-\eta$ for $s>0$ and $\dot{e} \geq \eta<0$. Consequently, the crossing of the trajectory of the border of the vicinity $e=\delta$ until $\dot{e} \leq-\eta$ for $s>0$, and of $e=-\delta$ to $e=\delta$ for $s=0$ occurs in finished time. For the other areas where $|e|>\delta$ one can conclude from Eq. (34) that $\mathrm{s}=0$ can be reached in finished time as long as $\dot{e} \leq-\eta$ for $s=0$ and $\dot{e} \geq \eta$ for $s=0$.

\section{Design of FTSMC for Kaplan hydroturbine governor sys- tem}

By considering the same equation Eq. (17), The concept of fast sliding surface proposed by $[6,7,9,10,12]$ as follows: Consider the tracking error:

$$
\varepsilon=\omega-\omega_{r}
$$

The sliding manifold is defined as:

$$
\sigma=\dot{\varepsilon}+\phi \varepsilon+\Psi \varepsilon^{\frac{q_{3}}{p_{3}}}
$$

where $q_{3}>0$ and $p_{3}>0$ are odd integers that satisfy $0<\frac{q_{3}}{p_{3}}<1 ; \phi>0$; and $\Psi>0$ : Select the sliding manifold variable $\sigma=0$, then

$$
\dot{\varepsilon}=-\phi \varepsilon-\Psi \varepsilon^{\frac{q_{3}}{p_{3}}} .
$$

Asymptotic stability is obtained by using the following function of Lyapounov:

$$
V=\frac{1}{2} \sigma^{2}
$$

The differentiation of Eq. (40) and using Eq. (38), one obtains:

$$
\begin{aligned}
\dot{V} & =\sigma \dot{\sigma}=\sigma\left(\ddot{\varepsilon}+\phi \dot{\varepsilon}+\Psi \frac{q_{3}}{p_{3}} \varepsilon^{\frac{q_{3}}{p_{3}}-1} \dot{\varepsilon}\right) \\
\dot{V} & =\sigma\left(-6.8935 x_{1}-6.2138 x_{2}+4.66 u\right. \\
& \left.-\ddot{\omega}_{r}-\phi \dot{\varepsilon}+\Psi \frac{q_{3}}{p_{3}} \varepsilon^{\frac{q_{3}}{p_{3}}-1} \dot{\varepsilon}\right)
\end{aligned}
$$

Taking $f_{0}(x)=-15.3031 x_{1}-6.2138 x_{2}$ and $g_{0}(x)=4.66$. The control law by FTSMC is given in the form:

$$
\begin{aligned}
u_{0}= & \frac{1}{g_{0}(x)}\left(-f_{0}(x)+\ddot{\omega}_{r}-\phi \dot{\varepsilon}-\Psi \frac{q_{3}}{p_{3}} \varepsilon^{\frac{q_{3}}{p_{3}}-1} \dot{\varepsilon}\right) \\
& -\varphi \sigma-\gamma \operatorname{sign}(\sigma)
\end{aligned}
$$

Where $\phi=19, \Psi=2, p_{3}=4, q_{3}=2, \varphi=90$ and $\varphi=40$. The substitution of Eq. (43) into Eq. (42), the derivative of $s$ is rewritten as:

$$
\dot{\sigma}=-g_{0}(x) \varphi \sigma-\gamma g_{0}(x) \sigma^{\frac{q_{3}}{p_{3}}}
$$

Therefore, we have define the Lyapunov function $V=\frac{1}{2} \sigma^{2}$ and take the Eq. (33) ,that is

$$
\dot{V}=s s=-g_{0}(x) \varphi \sigma^{2}-\gamma g_{0}(x) \sigma^{\frac{q_{3}}{p_{3}}+1}
$$

$$
\dot{V}=-\varphi^{\prime} \sigma^{2}-\gamma^{\prime} \sigma^{\frac{q_{3}}{p_{3}}+1}
$$


Where $\varphi^{\prime}=g_{0}(x) \varphi, \gamma^{\prime}=\gamma g_{0}(x)$.

Then $\gamma^{\prime}>0$ and $\operatorname{dot} V=-\varphi^{\prime} \sigma^{2}-\gamma^{\prime} \sigma^{\frac{q_{3}}{p_{3}}+1} \leq 0$. According to Lyapunov stability theory, the system is stable.

From the transfer functions Eq. (2), Eq. (5), Eq. (6) and Eq. (7), We obtain the models Simulink of hydroturbine governor system ( Fig.3 and Fig.4 ).

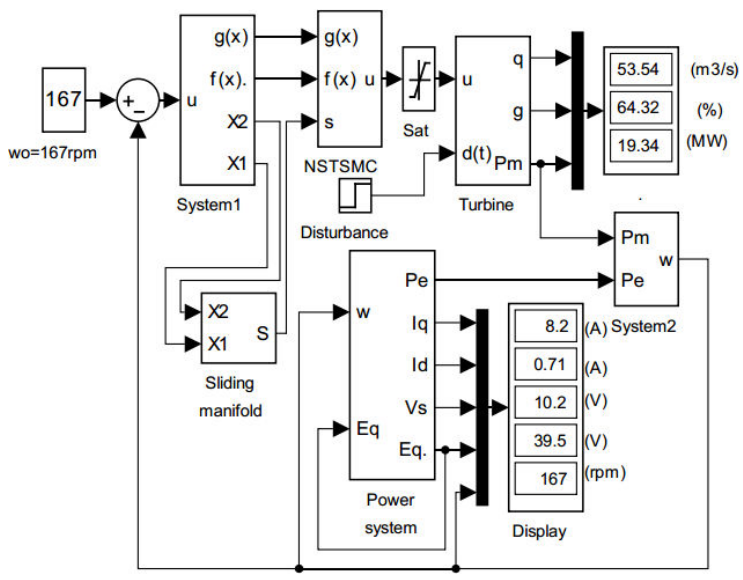

Fig. 3. Simulink model of the of hydroturbine governor system controlled by NTSMC.

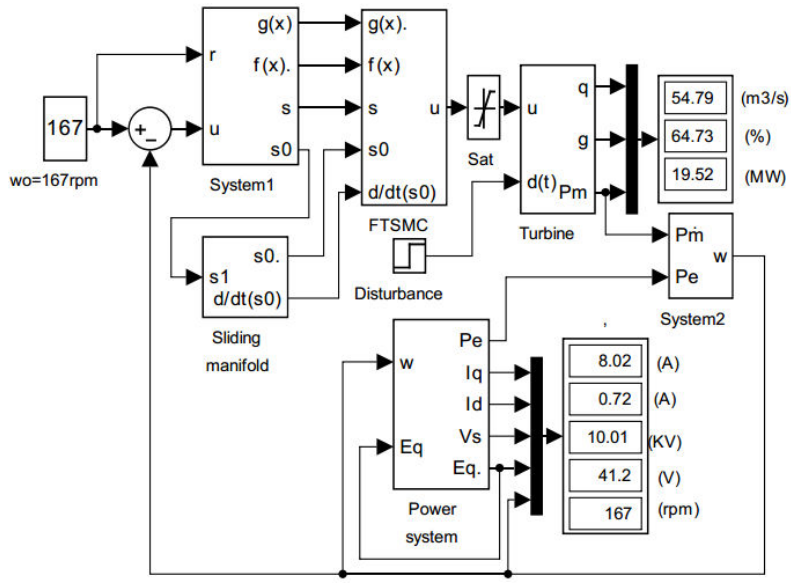

Fig. 4. Simulink Model of the of hydroturbine governor system controlled by FTSMC.

\section{Simulation Results.}

We simulate during 30 seconds the response of the closed loop system of turbine governor ( Fig.3 and Fig.4 for a level nominal speed turbine $167 \mathrm{rpm}$. It is noted that speed of the turbine is well maintained with the value $167 \mathrm{rpm}$. Fig.6 show the evolution of sliding manifold for the NTSMC and FTSMC controllers.

By observing Fig.5 which represents the response of the system under nominal operation we let us can see that the system is stable and that the speed of the turbine is maintained at $167 \mathrm{rpm}$, which corresponds to the value provided by the manufacturer of the turbine.

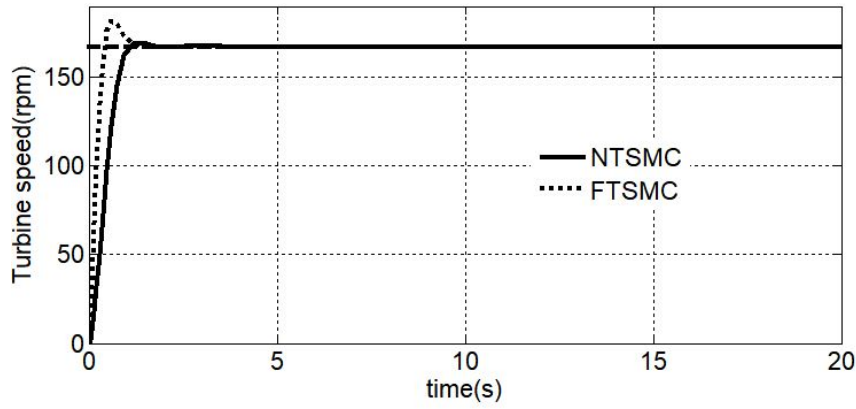

Fig. 5. Comparison results of turbine speed for the NTSMC and FTSMC controllers.

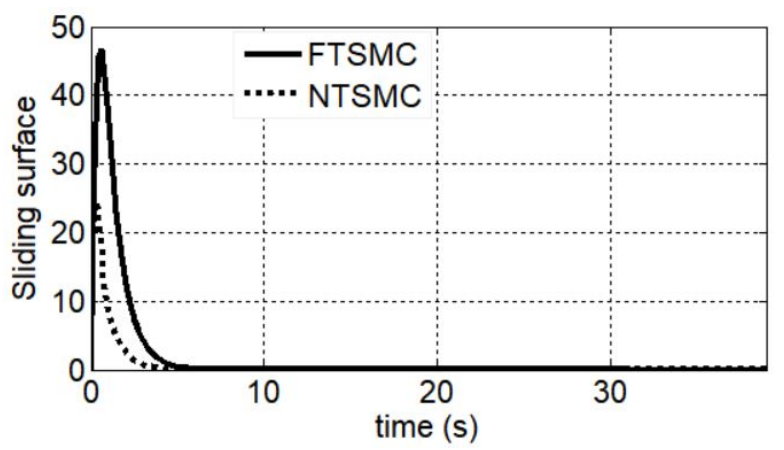

Fig. 6. Evolution of sliding manifold for the NTSMC and FTSMC controllers.

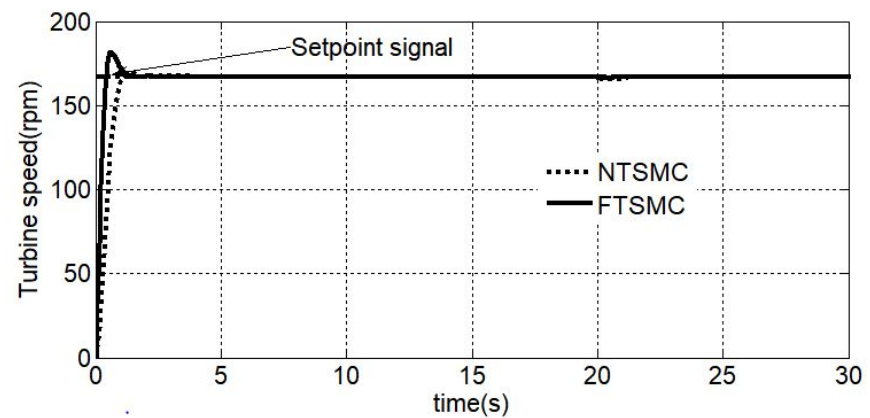

Fig. 7. Comparison results of turbine speed under load torque disturbance for the NTSMC and FTSMC controllers.

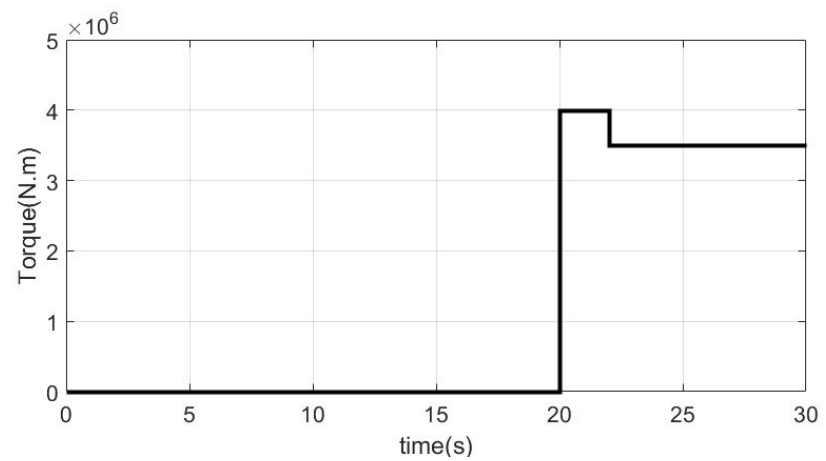

Fig. 8. load torque disturbance .

The load torque disturbance is a spread out signal repre- 
sented on Fig.8; this reflecting the load change during a sudden change in the power absorbed by the network appearing at 20 s.

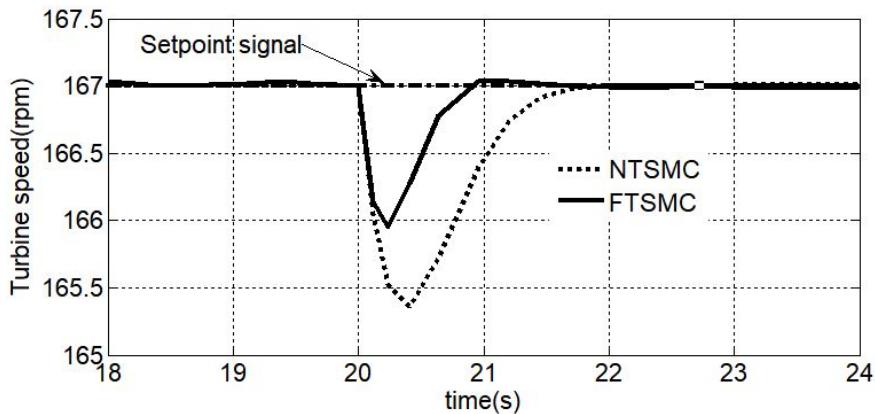

Fig. 9. Comparison results of turbine speed (zoom) under load torque disturbance for the NTSMC and FTSMC controllers.

A comparative study of the speed of the turbine (Fig.8) for the FTSMC and NTSMC after the appearance of the load torque disturbance was made in this table III. It is noticed that after $1,2 \mathrm{~s}$ only the system controlled by FTSMC reacts and the trajectory of the signal of the speed returned back to the standard base speed. The simulation results clearly show that the set-point tracking and disturbance rejection are achieved and it offers robustness.The FTSMC can make so that the turbine has a minimal influence in the event of load torque disturbance.

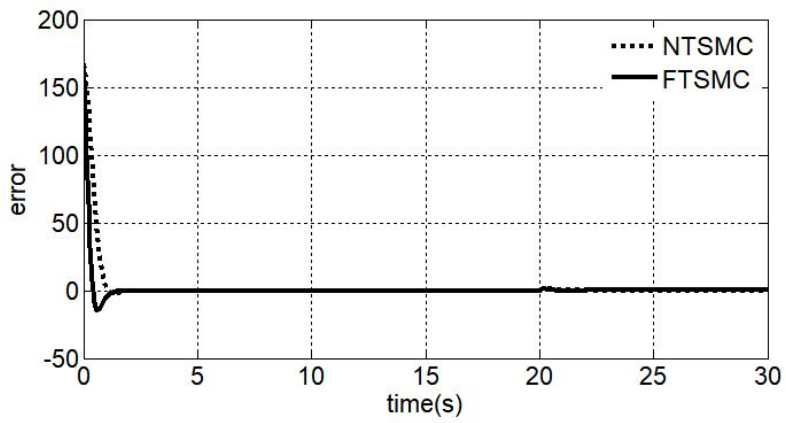

Fig. 10. The disturbance (load torque disturbance) rejection responses.

After the simulation results of each order, one can present a table which represents the overshoot, rise time and sliding time. Then, the table is given below:

TABLE III

COMPARISON OF OVERSHOOT, RISE TIME AND SLIDING TIME ACCORDING TO NTSMC AND FTSMC CONTROLLERS.

\begin{tabular}{llll} 
Controllers & Overshoot $\%$ & $\begin{array}{l}\text { Rise } \\
\text { time(s) }\end{array}$ & $\begin{array}{l}\text { Sliding } \\
\text { time }(\mathrm{s})\end{array}$ \\
\hline NTSMC & 6.4 & 2.2 & 0.63 \\
FTSMC & 4.1 & 1.75 & 0.45 \\
\hline
\end{tabular}

It appears according to Table III and simulation results that: the FTSMC also makes it possible to ensure convergence in finite time with a rise time short. On the other hand, it makes it possible to maintain good pursuit performances of continuation in the presence of external disturbances compared

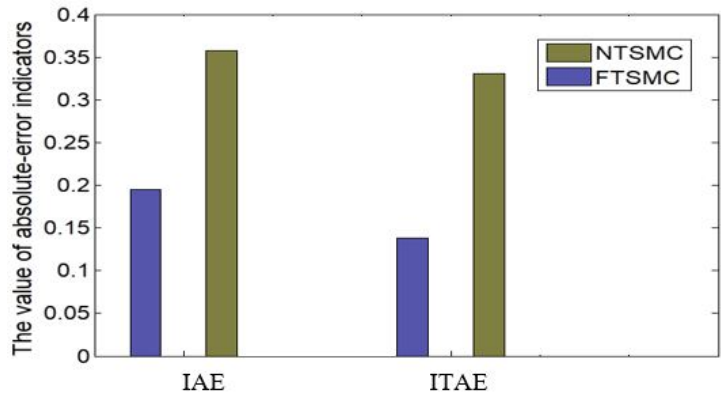

Fig. 11. The absolute-error indicators of the NTSMC and FTSMC controllers.

TABLE IV

THE COMPARISON OF FTSMC AND NTSMC CONTROLLERS UNDER PERIODIC ORBIT TRACKING.

\begin{tabular}{lll} 
Controllers & IAE & ITAE \\
\hline NTSMC & 0.3577 & 0.3309 \\
FTSMC & 0.1953 & 0.1386 \\
\hline
\end{tabular}

to control law by NTSMC . It is clear that the FTSMC makes it possible to obtain a fast convergence and a better precision than the NTSMC.

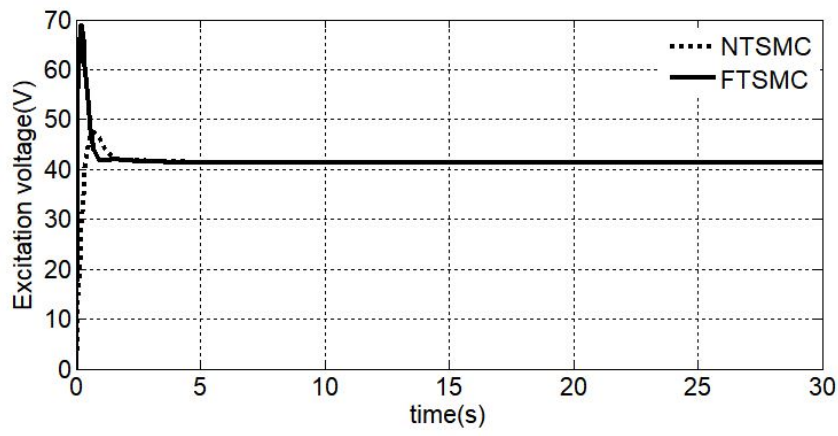

Fig. 12. Comparison results of exciter voltage for the NTSMC and FTSMC controllers.

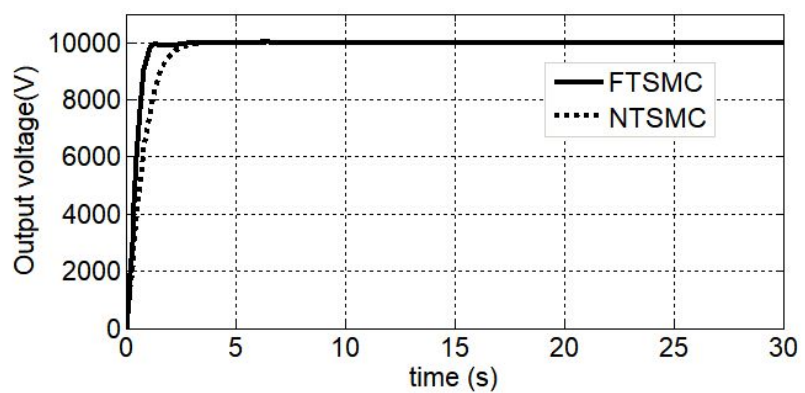

Fig. 13. Comparison results of output voltage for the NTSMC and FTSMC controllers.

The evolution of the disturbance (load torque disturbance) rejection responses is shown in the Fig.10. The sliding surface simulation plot is shown in the Fig.6, one can see that precision of the sliding variable is more in the case of FTSMC. Order FTSM shows a good stability of turbine speed and to 


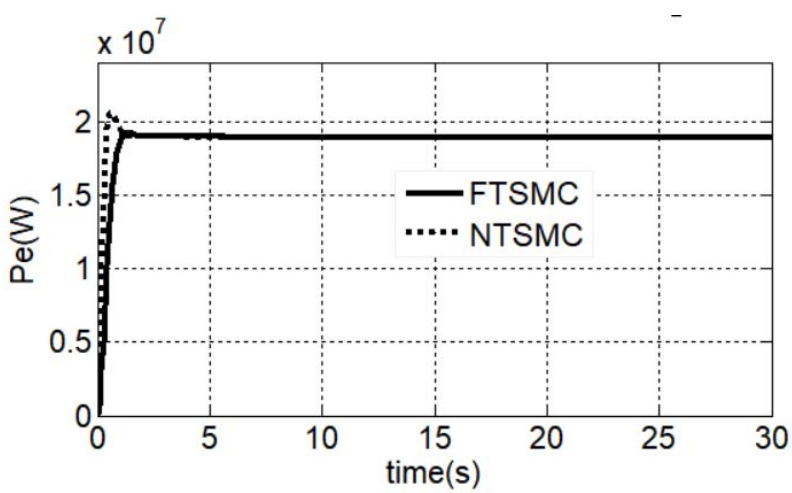

Fig. 14. Comparison results of real power output at the generator terminals for the NTSMC and FTSMC.

ensure a good convergence in finite time. The figures ( Fig.12, Fig.13 and Fig.14 ) present respectively the comparison results of exciter input voltage, output voltage and the real power output at the generator terminals for the NTSMC and FTSMC controllers.

In order to evaluate the steady state error, we consider the integral of the absolute value of error (IAE) and integral of the time weighted absolute error (ITAE) performance index . The IAE and ITAE performance index are defined respectively :

$$
I A E=\int_{0}^{\infty}|e(t)| d t, I T A E=\int_{0}^{\infty} t|e(t)| d t
$$

Where $\mathrm{e}$ is the difference between actual speed of the hydroturbine and reference signal. Plots for the IAE and ITAE clearly indicates that the FTSM is much better (Fig.11) .

\section{CONCLUSiON}

In this article the fast terminal sliding mode controller (FTSMC) approach was investigated for Kaplan hydroturbine governor System. Using sliding manifold, the stability analysis is demonstrated based on Lyapunov function. According to the results obtained, Compared with nonsingular terminal sliding mode controller (NTSMC), one noticed that the robustness of FTSMC proposed make it possible to guarantee the high precision of the speed of the turbine, but also to keep a great stability the speed of the turbine.

\section{REFERENCES}

[1] A. Yeremou Tamtsia, A. H. Samba,L. Nneme Nneme, Application of Higher Order Sliding Mode Observer and Super Twisting Observer based Super Twisting Control in Hydroelectric Power Plants, International Journal of Recent Technology and Engineering, vol.8, no.2, pp. 3649$3653,2019$.

[2] X.Yuan and Z.Chen, Sliding mode controller of hydraulic generator regulating system based on the input/output feedback linearization method, Mathematics and Computers in Simulation, no.119, pp. 18-34,2016.

[3] J.A.Laghari and H.Mokhlis, A fuzzy based load frequency control for distribution network connected with mini hydro power plant, Journal of Intelligent and Fuzzy Systems, vol.26, no.3, pp. 1301-1310,2014.

[4] S.Amirkhani and S.Mobayen , Fast terminal sliding mode tracking control of nonlinear uncertain mass-spring system with experimental verifications, International Journal of Advanced Robotic Systems, vol.16, no.12, pp. 1-10,2019.

[5] I.Yazici and E.Yaylaci, Fast and robust voltage control of DC-DC boost converter by using fast terminal sliding mode controller, IET Power Electronics, vol.9, no.1, pp. 120-125,2016.
[6] S.Li and M.Zhou, Design and implementation of terminal sliding mode control method for PMSM speed regulation system, IEEE Trans. Ind. Informt, vol.9, no.4, pp. 1879-1891,2013.

[7] S.Chen and Z.Su, lobal Fast Terminal Sliding Mode Control of a Brushless DC Motor Actuator Using Time-delay Estimation, IEEE International Conference on Computer Application and System Modeling, vol.2,2010.

[8] S.Wu and J.Zhang, A terminal sliding mode observer based robust backstepping sensorless speed control for interior permanent magnet synchronous motor, Internationnal Journal of Control, Automation and Systems, vol.16, no.4, pp. 2743-2753,2018.

[9] J.Gambhire and S.Kanth, Robust fast finite-time sliding mode control for industrial robot manipulators, International Journal of Dynamics and Control, vol.7, no.3, pp. 607-618,2019.

[10] E.Karam and W.Zhang, Finite-time Adaptive Integral Backstepping Fast Terminal Sliding Mode Control Application on Quaddrotor UAV ,Internationnal Journal of Control, Automation, and Systems, vol.18,no.2, pp. 415-430,2020.

[11] Y.Feng and X.Yu, Non-singular terminal sliding mode control of rigid manipulators, Automatica, vol.38, no.12, pp. 2159-2167, 2002.

[12] X.Yu and M.Zhihong, Fast terminal sliding-mode control design for nonlinear dynamical systems, IEEE Transactions on Circuits and Systems , vol.49, pp. 261-264, 2002.

[13] M.Zribi and M.Al-Rifai, Transient Stability of Power Systems Using Sliding Mode Controllers, Journal of Applied Sciences, vol.6, no.3, pp. 580-590, 2006.

[14] L.Wei and C.Si-Yi, Double Closed-loop Integral Terminal Sliding Mode for a Class of Underactuated Systems Bassed on Sliding Mode Observer Internationnal, Journal of Control, Automation, and Systems, vol.18, no.2, pp. 339-350, 2020.

[15] M.Vinatoru and E.Iancu, Control System for Kaplan HydroTurbine, Proceedings of the 4th WSEAS/IASME International Conference on Dynamical systems and control, Corfu, Greece, vol.19, pp. 73-78, 2008.

[16] J.Zhao and L.Wang,, Dynamic Model of Kaplan Turbine Regulating System Suitable for Power System Analysis, Mathematical Problems in Engineering, pp. 1-12, 2015.

[17] Kosterev and Dmitry, Hydro turbine-governor model validation in pacifc northwest, IEEE Transactions on Power Systems, vol.19, pp. 11441149, 2004.

[18] M.Brezovec and I.Kuzle, Nonlinear digital simulation model of hydroelectric power unit with Kaplan turbine, IEEE Transactions on Energy Conversion, vol.21, no.1, pp. 235-241, 2006.

[19] Z.Zohra and A.Mustapha, Variable Structure Control for Voltage/Speed Control in Power System, Journal of Automation and Control, vol.1, no.1, pp. 26-33, 2013.

[20] Bensenouci and Ahmed, Design of a robust iterative PID controller for power system stabilizer using H2-Norm,Journal of Electrical Systems, vol.7, no.3, pp. 25-39, 2011.

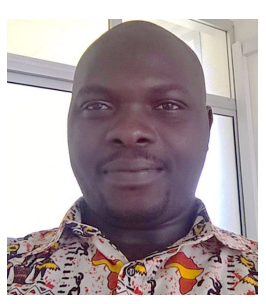

Samba Aime Herve Completed MSc degree in Electronic and Instrumentation from Douala University, Cameroon, in 2016. Currently, he is pursuing for his $\mathrm{PhD}$ degree in the Department of Industrial robotics at Faculty of Industrial Engineering, University of Douala, Cameroon. His research interests robust control ,networked control systems, Sliding mode control and observer-based control. 


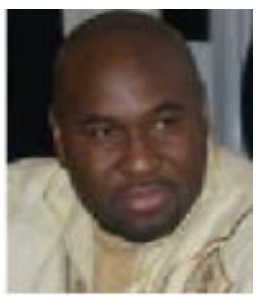

Yeremou Tamtsia Aurelien Received the Master Degree in process engineering and the Ph.D. degree in vision and robotic from agro- food processing engineering school (ENSAI - Cameroon) and Blaise Pascal university Clermont- Ferrand (France) respectively. From 2013, he held an academic position in the Department of Industrial robotics at Faculty of Industrial Engineering, University of Douala (Cameroon), as Lecturer. His current researches lie on Robot Control, robust control, industrial instrumentation and regulations technologies of both deterministic and stochastic dynamic processes.

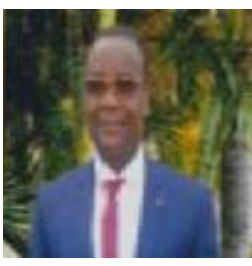

Nneme Nneme Leandre Received the Master Degree in electrical and computer science engineering and the Ph.D. degree in Systems and Automation from Ecole Polytechnique of Montreal (Canada) in 1993 and 1998 respectively. From 1998, he held an academic position in the Advanced Teacher is Training College for Technical Education (ATTCTE) of Douala (Cameroon), as senior Lecturer and Director of the ATTCTE. His current researches lie on Robot Control, industrial instrumentation technologies and dynamic processes. remote control of both deterministic and stochastic

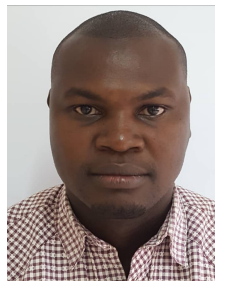

Korassaï Received a Teacherś Diploma for Technical Education Grade Two in Electronics from Advanced Teacherś Training College for Technical Education of Douala (Cameroon) and a Master's degree in electrical engineering from University of Douala, Cameroon, in 2011 and 2013 respectively. $\mathrm{He}$ is currently working toward $\mathrm{ahD}$ in electrical engineering in Laboratory of Energy, Signal, Imaging and Automatic of the Faculty of Sciences at the University of Ngaoundere, Ngaoundere, Cameroon. $\mathrm{He}$ is a Certified in Management of Vocational Training Centre, Korea Chamber of Commerce and Industry (KCCI - Republic of Korea since 2014 and from 2015, he is the Head of Maintenance Department at Advanced Vocational Training Centre of Limbe (Cameroon). His current researches lie on robust control, industrial instrumentation and and renewable energy. 